\title{
Strategic Analysis of Terrorism
}

\author{
Daniel G. Arce and Todd Sandler
}

\begin{abstract}
Two areas that are increasingly studied in the game-theoretic literature on terrorism and counterterrorism are collective action and asymmetric information. One contribution of this chapter is a survey and extension of continuous policy models with differentiable payoff functions. In this way, policies can be characterized as strategic substitutes (e.g., proactive measures), or strategic complements (e.g., defensive measures). Mixed substitute-complement models are also introduced. We show that the efficiency of counterterror policy depends upon (i) the strategic substitutes-complements characterization, and (ii) who initiates the action. Surprisingly, in mixed-models the dichotomy between individual and collective action may disappear. A second contribution is the consideration of a signaling model where indiscriminant spectacular terrorist attacks may erode terrorists' support among its constituency, and proactive government responses can create a backlash effect in favor of terrorists. A novel equilibrium of this model reflects the well-documented ineffectiveness of terrorism in achieving its stated goals.
\end{abstract}

\section{Introduction}

Terrorism is a form of asymmetric conflict where terrorists do not have the resources necessary to engage their adversaries in direct conflict. Consequently, terrorists act strategically and use violence against civilians in order to attain political, ideological or religious goals. Terrorism is a tactic of intimidation of a target audience beyond

Daniel G. Arce

School of Economic, Political and Policy Sciences, University of Texas at Dallas, $800 \mathrm{~W}$. Campbell Road, Richardson, TX 75080-3021, USA, e-mail: darce@utdallas.edu

Todd Sandler

Vibhooti Shukla Professor of Economics and Political Economy, School of Economic, Political and Policy Sciences, University of Texas at Dallas, 800 W. Campbell Road, Richardson, TX 750803021, USA, e-mail: tsandler@utdallas.edu 
that of the immediate victims. Viewed from this perspective, it is natural to study terrorism and counterterrorism through the lens of game theory, where terrorists and their targets are assumed to choose their tactics rationally, and to recognize their strategic interdependence in determining the outcomes of their actions. Note that we are not assessing whether terrorists' ultimate goals are rational or desirable; the preferences of terrorists and target governments are taken as given. What game theory presumes is that, ultimately, terrorists and target governments will select tactics and policies that minimize costs, maximize damage, effectively signal their intent, or hide their capabilities, thereby reflecting a form of procedural rationality for attaining their goals.

Two areas that are increasingly studied in the literature on terrorism and counterterrorism are collective action and asymmetric information. Collective action may refer to the efficient coordination of counterterror tactics by target governments and/or the sharing of tactical information and techniques by terrorists groups. Collective action is an issue because rational action by individual governments or terrorists may be at odds with the goals of the larger group. For example, as successful proactive counterterror policies reduce the ability of a terrorist group to attack any target (e. g., retaliating against a state sponsor), some governments may be willing to free ride on the policies of governments that are more likely to be attacked, leading to a case of suboptimal proactive policy at the global level. By contrast, defensive counterterror policies (e.g., air marshals) may push terrorist activity elsewhere, either to target a country's citizens on foreign soil, or to target another country altogether. Such negative externalities are often overprovided. Surveys of game theoretic models of discrete choices between proactive and defensive policies are contained in $[3,16$, 17]. In Sect. 2 of this chapter, we present a unifying framework when payoffs are differentiable in these choices, thereby introducing the notion of strategic complements and substitutes to assess counterterror policy.

When nations select counterterror policies without fully knowing the policies selected by their counterparts, the corresponding game is categorized as one of imperfect information. Consequently, Sect. 2 contains a characterization of the dichotomy of counterterror policy under imperfect information. When this assumption is relaxed - corresponding to a situation of perfect information - one of the parties can select their policy knowing that the other party will react optimally to it. Section 2 characterizes when this leader-follower framework is desirable.

Governments may also construct strategic counterterror policy without fully understanding the intent of the terrorists whom they face. Terrorists may be primarily politically motivated, in which case concessions may be an effective counterterror policy; or they may seek maximalist objectives such as completely overturning the tenets upon which a country is governed. Politically-motivated terrorists have an incentive to mimic the attacks of more militant ones if they believe that this will quickly lead to concessions. Moreover, militant terrorists may mimic the lessdamaging attacks typically associated with politically-motivated terrorists if this allows them to catch the target government unprepared in future periods. Such a scenario is known as a signaling game, where the government has incomplete information about the type of terrorists whom it is facing. In Sect 3, we introduce and 
analyze a signaling game that is consistent with two stylized facts normally associated with terrorism. First, terrorism is rarely successful when measured against the concessions that the terrorists seek $[1,2]$. Second, even in the absence of concessions, terrorists engage in campaigns that may provide future resources, depending on how the target population reacts to the government's counterterror policy.

\section{Strategic Substitutes and Strategic Complements in the Study of Terrorism}

Game-theoretic models use continuous choice variables for strategic adversaries to illuminate various counterterrorism policies [17, 20]. A recurrent theme is the notion of strategic substitutes or strategic complements, which we illustrate with a number of terrorism-based examples. Some notation and definitions are required. Throughout the analysis, we assume just two players, denoted by $i$ and $j$ and/or 1 and 2 . The mathematical analysis can be easily extended to $n$ players, while the graphical analysis necessitates a symmetry-of-players assumption to be extended beyond two players.

Player $i$ either maximizes a payoff function, $U_{i}\left(x_{i}, x_{j}\right)$, or else minimizes a cost function, $C_{i}\left(x_{i}, x_{j}\right)$, for $i$ and $j, i \neq j$, where $x_{i}$ and $x_{j}$ are the respective agent's continuous choice strategies. Without loss of generality, we express our definitions in terms of the cost-minimization scenario. Player $i$ 's best response to agent $j$ 's choice, $x_{j}$, is equal to:

$$
B R_{i}\left(x_{j}\right)=\arg \min _{x_{i}} C_{i}\left(x_{i}, x_{j}\right),
$$

while player's $j$ 's best response to agent $i$ 's choice, $x_{i}$ is equal to

$$
B R_{j}\left(x_{i}\right)=\arg \min _{x_{j}} C_{j}\left(x_{i}, x_{j}\right) .
$$

The best response for player $i$ is found by solving the implicit function,

$$
\frac{\partial B R_{i}}{\partial x_{i}}=\frac{\partial C_{i}\left(x_{i}, x_{j}\right)}{\partial x_{i}}=0
$$

associated with Eq. (1). A similar implicit function arises from Eq. (2) and applies to the best response for player $j$. The following definition is essential:

Definition 1. Strategy profile $\left(x_{i}^{N}, x_{j}^{N}\right)$ is a Nash equilibrium if and only if $x_{i}^{N} \in$ $\arg \min _{x_{i}} C_{i}\left(x_{i}, x_{j}^{N}\right)$ and $x_{j}^{N} \in \arg \min _{x_{j}} C_{j}\left(x_{i}^{N}, x_{j}\right)$.

At a Nash equilibrium, each agent's choice must be a best response to the other agent's best response, so that neither agent would unilaterally want to change its choice variable, if afforded the opportunity. When the two agents' best-response curves are displayed on a diagram, the Nash equilibrium corresponds to the intersection of these best-response curves. 
Given this background, we now define the essential concepts of strategic substitutes and strategic complements $[5,6]$.

Definition 2. Strategies $x_{i}$ and $x_{j}$ are strategic substitutes if the slopes of the bestresponse functions are negative: $\partial B R_{i} / \partial x_{j}<0$ and $\partial B R_{j} / \partial x_{i}<0$.

Definition 3. Strategies $x_{i}$ and $x_{j}$ strategic complements if the slopes of the bestresponse functions are positive: $\partial B R_{i} / \partial x_{j}>0$ and $\partial B R_{j} / \partial x_{i}>0$.

From an economic viewpoint, strategic substitutes indicate that the other agent's action can replace the need for one's own action. Efforts to free ride by cutting down on one's contributions to an activity (e. g., air pollution abatement) as others contribute is an example. In contrast, strategic complements imply that actions by one agent encourage the other agent to act. An arms race between two adversaries reflects strategic complements, as does exploitation of an open-access resource, such as an oil pool. In the latter case, each exploiter tries to pump out more of the oil before the pool runs dry - increased efforts by one merely motivates increased efforts by the other.

\subsection{Proactive Counterterrorism Measures}

This first example follows from the analysis of Sandler and Siqueira [19], where two nations are attacked by the same terrorist network. This scenario is descriptive of the al-Qaida network that conducts operations throughout much of the world. As such, a country's assets - its people or property - are at risk at home and abroad. With a global terrorist threat, efforts to secure one country's borders may displace the attack abroad. Proactive measures by either country to destroy the terrorists' infrastructure, to capture their operatives, or to cut off their finances will weaken the terrorist threat for both countries and secure their assets at home and abroad.

The objective function of targeted country $i$ consists of three cost components as it chooses its level of proactive effort, $\theta_{i}$, against the common terrorist threat. First, country $i$ incurs a proactive cost of $G\left(\theta_{i}\right)$ where $G^{\prime}\left(\theta_{i}\right)>0$ and $G^{\prime \prime}\left(\theta_{i}\right)>0$. Second, country $i$ endures an expected cost from attacks at home, which equals $\pi_{i} l\left(\theta_{i}\right)$ where $\pi_{i}$ is the likelihood of a home attack and $l\left(\theta_{i}\right)$ is the loss from such an attack. Proactive measures reduce these losses by weakening the terrorists so that $l^{\prime}\left(\theta_{i}\right)<0$. The likelihood of an attack depends on the proactive efforts in country $i$ and $j$ where $\partial \pi_{i} / \partial \theta_{i}<0, \partial \pi_{j} / \partial \theta_{i}<0$, and $\partial^{2} \pi_{i} / \partial \theta_{i} \partial \theta_{j}>0$ for $i, j$, and $i \neq j$. Offensive antiterrorist actions in either country reduces the risk of an attack everywhere. The cross partial indicates that there is a diminishing return to effort as both countries act. Third, proactive measures limit the expected losses to country $i$ abroad, denoted by $\pi_{j} v\left(\theta_{j}\right)$, where $v^{\prime}\left(\theta_{j}\right)<0$. Thus, country $i$ must choose its proactive level, $\theta_{i}$, to minimize its costs, $C_{i}$ :

$$
\min _{\theta_{i}} C_{i}\left(\theta_{i}, \theta_{j}\right)=G\left(\theta_{i}\right)+\pi_{i} l\left(\theta_{i}\right)+\pi_{j} v\left(\theta_{j}\right) .
$$


The first-order conditions of Eq. (4) implicitly defines the best response, $B R_{i}$, of country $i$ 's choice of $\theta_{i}$ in terms of the level of country $j$ 's proactive response, $\theta_{j}$.

To establish that this proactive choice results in strategic substitutes, we apply the implicit function rule to $\partial C_{i} / \partial \theta_{i}=0$ to find: ${ }^{1}$

$$
\frac{\partial B R_{i}}{\partial \theta_{j}}=\frac{-l^{\prime}\left(\theta_{i}\right) \frac{\partial \pi_{i}}{\partial \theta_{j}}-v^{\prime}\left(\theta_{j}\right) \frac{\partial \pi_{j}}{\partial \theta_{i}}-l\left(\theta_{i}\right) \frac{\partial^{2} \pi_{i}}{\partial \theta_{i} \partial \theta_{j}}-v\left(\theta_{j}\right) \frac{\partial^{2} \pi_{j}}{\partial \theta_{i} \partial \theta_{j}}}{\partial^{2} C_{i} / \partial \theta_{i}^{2}}<0 .
$$

The sign of Eq. (5) holds because the denominator is positive to satisfy the secondorder conditions for a minimum, while the numerator is negative. The latter follows from the negativity of all four terms, given the model's structure. Since the slope of $i$ 's best-response curve is negative and the same holds for $j$ 's best-response curve, proactive measures are strategic substitutes.

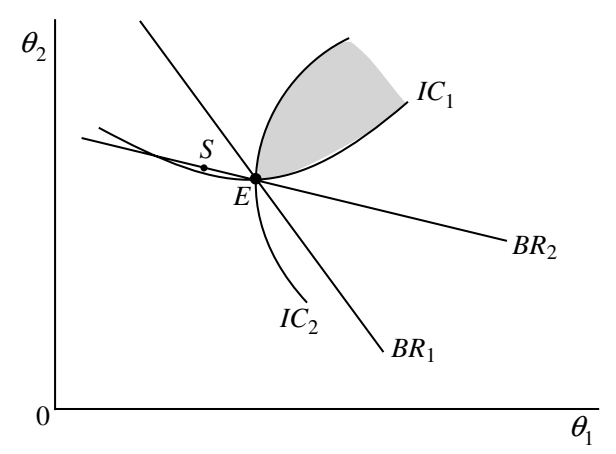

Fig. 1 Proactive measures

The downward-sloping reaction paths are illustrated in Fig. 1 for country 1 and 2. For simplicity, both paths are linearized and drawn to ensure a stable equilibrium. Reaction path $B R_{1}$ connects the minima for isocost curves of country 1 - where $I C_{1}$ is one such curve. The area above $I C_{1}$ indicates lower cost for country $1,{ }^{2}$ and hence greater welfare, as country 2 increases its proactive efforts for each level of $\theta_{1}$. Since country 2's isocost curves are translated by $90^{\circ}, 2$ 's isocost curves are C-shaped and curves further to the east of the vertical axis denote a higher level of 2's well-being as it prospers from country 1's proactive measures. The Nash equilibrium is at $E$. The shaded area formed by $I C_{1}$ and $I C_{2}$ indicates welfare-improving proactive allocations by both countries, compared with the Nash equilibrium. As shown, the Nash equilibrium results in an underprovision of offensive measures, which follows because both countries fail to account for the benefits that their offensive efforts confer on the other targeted country. Next suppose that country 1 engages in leadership behavior, in which it takes the follower's (country 2's) best-response path as

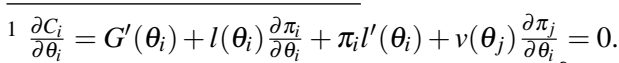

2 This follows because $\frac{\partial C_{i}}{\partial \theta_{j}}=l\left(\theta_{i}\right) \frac{\partial \pi_{i}}{\partial \theta_{j}}+v\left(\theta_{j}\right) \frac{\partial \pi_{j}}{\partial \theta_{j}}+\pi_{j} v^{\prime}\left(\theta_{j}\right)<0$. 
its constraint and seeks a tangency between its isocost curve (not displayed) and $B R_{2}$ at, say, point $S$. At $S$, country 1 gains at 2's expense. Moreover, the overall level of proactive measures is even smaller than the suboptimal level at $E$ [19]. If both countries act strategically by moving their best-response curves downwards, then both become worse off, as the underprovision of proactive measures becomes greater. Thus, game theory shows the tendency to underprovide offensive actions in a multi-target environment; hence, the need for international cooperation becomes clear.

The two-country proactive game can be extended to allow for backlash when terrorists protest proactive measures against other terrorists by launching new attacks [24]. For example, the London transport suicide bombings on 7 July 2005 supported a beleagued al-Qaida network, which had been greatly stressed since 9/11. If two countries engage in proactive responses, then the more aggressive country is anticipated to draw the backlash attack. With the introduction of backlash, the best-response curves are downward sloping for two reasons - free riding on others' proactive responses and the avoidance of backlash. Figure 1 still applies and proactive measures remain strategic substitutes. Siqueira and Sandler [24] show that strategic voting on the part of the country's population will shift the best-response curves downward and exacerbate the suboptimality resulting from free riding and backlash avoidance.

\subsection{Defensive Countermeasures: Globalized Threat}

Next, we turn to a situation in which each of two nations take defensive countermeasures in the hopes of shifting terrorist attacks to a different country. The desirability of this strategy depends, in part, on the country's relative interests at home and abroad. If attacks are more costly at home than abroad, then actions to transfer attacks may be especially strong. Sandler and Siqueira [19] show that the same basic cost-minimizing objective in Eq. (4) applies with some small reinterpretation. The primary difference involves the probability of attack functions, $\pi_{i}$ and $\pi_{j}$, where $\partial \pi_{i} / \partial \theta_{i}<0, \partial \pi_{j} / \partial \theta_{j}<0, \partial \pi_{j} / \partial \theta_{i}>0$, and $\partial \pi_{i} / \partial \theta_{j}>0$. Greater defensive measures at home decrease the likelihood of a terrorist attack there, while these measures increase the likelihood of a terrorist attack abroad through transference, as terrorists seek out the softest target. The cross partials are now ambiguous:

$$
\frac{\partial^{2} \pi_{i}}{\partial \theta_{i} \partial \theta_{j}} \frac{>}{<} 0 \quad \text { as } \quad \theta_{i} \frac{<}{>} \theta_{j} .
$$

The expression for the slope of the best-response function is the same as Eq. (5), but its sign is typically positive, indicating strategic complements.

The orientation of the isocost curves are more difficult to pin down because there are more opposing influences in the defensive case - see [18, 19] for a full discussion. If the terrorism threat is globalized so that a nation experiences the same losses at home or abroad to its interests, then $l\left(\theta_{i}\right)=v\left(\theta_{j}\right)$ and $l\left(\theta_{j}\right)=v\left(\theta_{i}\right)$. In 


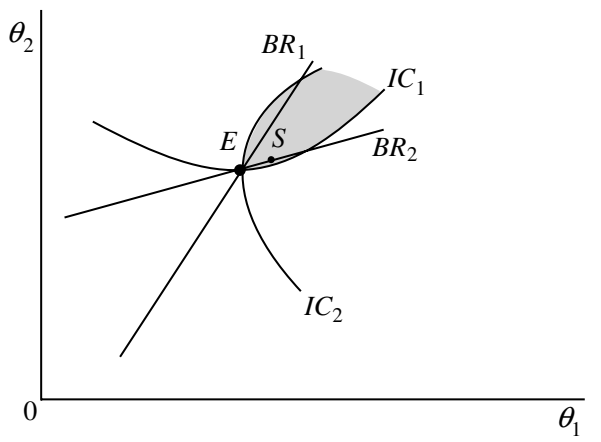

Fig. 2 Defensive countermeasures: globalized threat

this scenario, Fig. 2 applies in which the isocost curves have the same orientation as those in Fig. 1, but the $B R$ curves are now upward sloping indicating strategic complements. Once again, the shaded region in Fig. 2 depicts defensive combinations that are welfare-improving compared to the Nash equilibrium. The position of these welfare-dominating defensive allocations vis-à-vis nations' independent actions indicates a tendency toward too little defensive measures when the terrorism threat is globalized. This follows because countries do not account for the benefits that homeland security affords foreign residents, visitors, and foreign property. The position of the leader-follower equilibrium at $S$ (where country 1 leads) shows that strategic behavior by either or both nations can improve the allocation.

\subsection{Defensive Measures: No Collateral Damage}

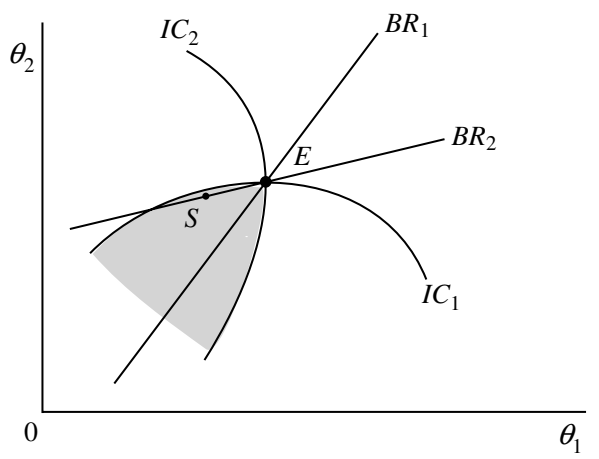

Fig. 3 Defensive race: no collateral damage

We now consider the defensive decision of two targeted countries, when attacks are host-country specific so that $v\left(\theta_{j}\right)=v^{\prime}\left(\theta_{j}\right)=0$ for $j=1,2$. This means that a 
country's assets are not targeted abroad, so that there is no collateral damage on foreign interests in a venue country. In this scenario, defensive external costs imposed on other countries involve the transference of an attack; that is, an increase in $\theta_{i}$ augments the likelihood that the attack will be transferred to a less vigilant country. The best-response curves are still upward sloping, indicative of strategic complements; however, the isocost curves reverse their orientation, with $I C_{1}$ being hill shaped and $I C_{2}$ being a reversed $C$. This case is displayed in Fig. 3, where country 1's (2's) welfare improves as $I C_{1}\left(I C_{2}\right)$ shifts down (leftward), so that the other targeted country is spending less on defense. As a consequence, fewer terrorist attacks are transferred. The shaded area represents welfare-improving allocations, which highlight that nations will over spend on defense and engage in a homeland security race to become more impregnable. For this case, nations will mutually gain by coordinating defensive decisions. Leader behavior by country 1 improves the welfare of both countries and provides a second-mover advantage to the follower, whose welfare improves by relatively more.

\subsection{Intelligence}

Intelligence gathered on a common terrorist threat presents two targeted countries with mutual benefits and costs. If intelligence is used to weaken the terrorist group, then both countries benefit, analogous to the first case of proactive measures. This suggests a situation of strategic substitutes and downward-sloping $B R$ curves, since ideally a country may be best off by free riding on the intelligence collected by the other country. Increased intelligence activity, $x$, by one country reduces the need for the other country to collect intelligence. Intelligence differs from proactive measures because intelligence gathering by another country may cause intelligence-collection cost, $c$, to the other country - i. e., $c_{i}\left(x_{j}\right)$, where $\partial c_{i} / \partial x_{j}>0$ for $i, j, i \neq j$. This follows because more agents in the field may result in crowding and the potential for mishap and wasted effort.

To capture this scenario, we represent country $i(=1,2)$ maximizing its welfare, $U_{i}$ :

$$
U_{i}=U_{i}\left[y_{i}, I\left(x_{i}, x_{j}\right)\right],
$$

where $y_{i}$ represents nonintelligence consumption and $I$ is intelligence gained from intelligence-gathering activity, $x_{i}$ and $x_{j}$, by the two countries. Each country or government faces the following budget constraint:

$$
x_{i} c_{i}\left(x_{j}\right)+y_{i}=Y_{i},
$$

where the price of $y_{i}$ is normalized to be 1 and $Y_{i}$ is the country's income. The budget constraint can be substituted into the objective function to give $i$ 's maximization problem: 


$$
\max _{x_{i}} U_{i}\left[Y_{i}-x_{i} c_{i}\left(x_{j}\right), I\left(x_{i}, x_{j}\right)\right]
$$

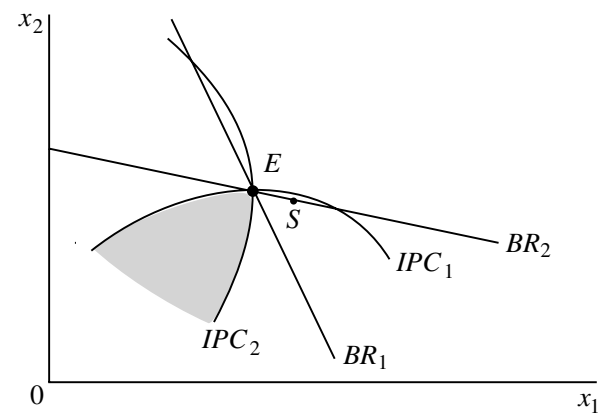

Fig. 4 Intelligence provision

Based on this maximization problem, the best-response curve can be derived and the slope shown to be negative under a wide range of scenarios. Moreover, the isoprofit curves $(I P C)$ can be shaped as in Fig. 4 if there is sufficient crowding cost for intelligence collection. As before, the shaded area denotes intelligence expenditures that are more desirable than the Nash equilibrium. Strategic behavior can result in inferior outcomes at $S$ or northeast of $E$ if practiced by both countries.

\subsection{Other Cases}

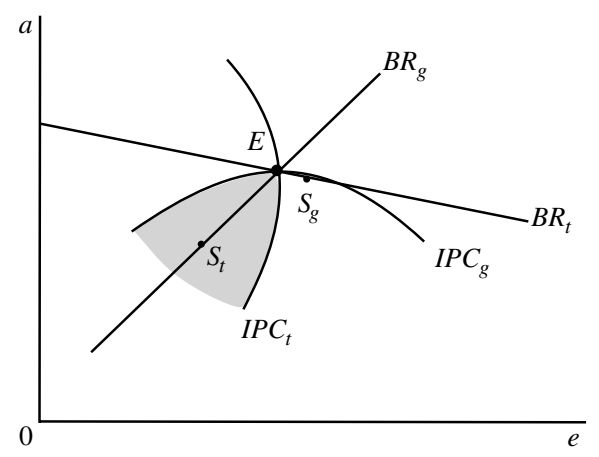

Fig. 5 Mixed case

Thus far, we examined two cases of strategic substitutes and two cases of strategic complements for various counterterrorism measures. For our final graphical example, we change the strategic agents to be the terrorists and a single targeted 
government. The terrorists choose a level of attacks, $a$, while the government exerts counterterrorism efforts, $e$. Siqueira and Sandler [23] present such models for which both the terrorists and the government are seeking support of members of the population. One of their models is displayed in Fig. 5, where the best-response curve of the government, $B R_{g}$, is upward sloping so that increased terrorist attacks are met with greater countermeasures. In contrast, the best-response curve of the terrorists, $B R_{t}$, is downward sloping: terrorists reduce attacks as the government augments its countermeasures. Thus, we have a mixed case where the two choice variables are strategic substitutes from the terrorist viewpoint and are strategic complements from the government viewpoint. For this mixed case, terrorist leadership results in an outcome $S_{t}$ in the welfare-improving region, while government leadership does not improve both players' welfare. Figure 5 shows that the consequences from strategic behavior depends on who initiates the action when players view the set of choice variables differently.

A wide variety of players can be examined for continuous games applied to terrorism. In an innovative analysis, Siqueira [22] investigates strategic interaction between a political and a military wing of a terrorist group. He distinguishes four scenarios, some of which involve strategic substitutes and strategic complements. If, for example, actions by the two wings are strategic complements, then government counterterrorism actions taken against the political wing can have a double dividend by decreasing both political and military terrorist activities.

Continuous choice also applies to multi-level games, where the strategic players may change at each stage [20]. The nature of the strategic substitutes and/or complements may also change at the various stages. Clearly, the analysis can be applied to a variety of terrorism scenarios and, in so doing, enlighten policymakers.

\section{Terrorist Signaling: Backlash and Erosion Effects}

In this section, we address the issue of direct interaction between terrorists and a government when the government is uncertain about the type of terrorists that it confronts. Specifically, terrorist attacks can be viewed as a form of costly signaling, where violence is used as a device to persuade and alter the target audience's beliefs about terrorists' commitment to their cause and their ability to impose costs $[4,10$, $13,16]$. Uncertainty often concerns whether terrorist goals are political or ideological $[1,9,21]$. We label terrorists as political ( $P$-types) when their goals are related to concrete political objectives, such as political self-determination or eviction of an occupying force. These would include the Irish Republican Army (IRA) and Palestine Liberation Army (PLO). Abrams [2] calls this a limited objective. Here, the defining feature is that terrorism is a pure cost for $P$-types, because the resources used for terrorism represent an opportunity cost relative to their nonviolent use to achieve concessions. By contrast, militant terrorists see attacks as an intrinsic benefit (e.g., jihad as a religious requirement or the necessity of a Marxist struggle). Militant terrorists ( $M$-types) have maximalist objectives corresponding to demands 
over ideology, either to completely transform the political system or annihilate the enemy [2]. Examples include Hamas and the Shining Path. Although some groups can be clearly characterized, many groups have idiosyncratic or a combination of limited and maximal demands (e.g., Hezbollah [2]), thereby creating uncertainty about the group's type. In such cases, there is a need for intelligence to understand the enemy.

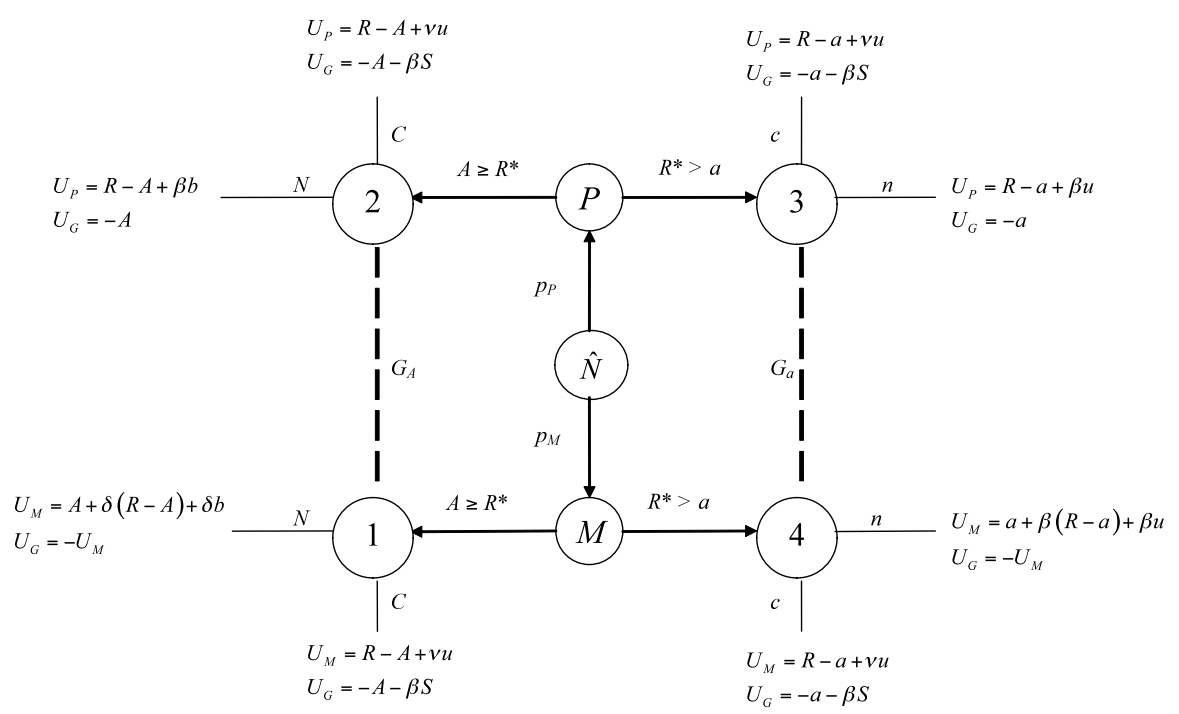

Fig. 6 Terrorist attacks as signals

Figure 6 is an example of a two-period signaling game where the government has incomplete information about its terrorist adversary. We use a two-period model because most terrorist groups are short-lived [15]. Nature moves first and selects the terrorists' type ( $M$ or $P$ ) according to a two-support probability distribution ( $p_{M}$ and $\left.p_{P}\right)$. Terrorists can either attack at or above a spectacular level, $A \geq R^{*}$, or below the spectacular level, $a<R^{*}$. Ex ante the government does not know the terrorist type, which is modeled as imperfect information about the move by nature $(\widehat{N})$. The dotted line labeled $G_{A}$ collects the set of nodes (1 and 2) reflecting this imperfect information after a spectacular attack, $A$. Analogously, $G_{a}$ is the information set that contains nodes 3 and 4 subsequent to non-spectacular attack, $a$. Following an attack $(A$ or $a)$, the government can either concede $(C$ or $c)$ or not $(N$ or $n)$. If the government does not concede, $M$-types expend all of their remaining resources in an attack, whereas $P$-types use their remaining resources for political goals.

Given the definition of the players and their strategies, we now turn to the payoffs. In Fig. 6, the payoffs to each terrorist type are written as $U_{P}$ and $U_{M}$, and to the government as $U_{G}$. The value of any attack enters negatively into the government's payoff and, as discussed below, this value enters into the terrorists' payoff according to the terrorists' type. Let $R$ denote the terrorists' first-period resources, common to 
both types and sufficient to mount a spectacular attack, $R \geq R^{*}$. In prior signaling models $[4,13,14,16]$, terrorists have resources exogenously available in both the first and second periods; however, part of the purpose of terrorism is to generate future resources and support $[1,8,12]$. Thus, we model terrorists' second-period resources, contingent upon their first-period actions and the response of the target government. A priori terrorists can expect a level of support equal to $u$, defined as the existing underlying support for the terrorist group. If terrorists attack below the spectacular level, then they garner this support. In the second period, $P$-types use this support for political means, with a baseline value of $\beta u$ where $\beta$ is the secondperiod discount factor. If the government concedes to attack $a$, then this support becomes $v u$ where $v>\beta$ corresponds to a "victory" effect on discounting. If, instead, the terrorist attacks at the spectacular level, $A$, then the underlying support is put at risk. Indeed, Abrams [2] identifies a self-defeating component of terrorism in which large-scale attacks undermine support because of the collateral damage they produce and their potential to miscommunicate the degree to which the supporting population can be appeased through limited concessions. For example, during 1968-72 the Tupamaros [Movimiento de Liberacion Nacional (MLN)] in Uruguay conducted acts of urban terrorism so brutal that they lost any semblance of popular support [7]. Similarly, the previously maximalist Islamic Group has renounced violence, coming to the conclusion that the unwarranted spilling of blood and wrecking of property runs counter to Islam [26]. Abrams [2] cites the finding in a 2005 Pew Research Center global attitudes poll that in most majority-Muslim countries surveyed, support for suicide bombing (which, on average, causes twelve times more deaths than do conventional attacks) and other acts of violence in defense of Islam has declined significantly since 2002 . We call this reduction in underlying support the erosion effect.

Of course, the purpose of terrorism is not to generate this self-defeating component, but instead to garner further support, primarily through reactions to the target government's response. Terror groups often use the politics of atrocity to produce further counter-atrocities that manifest themselves as backlash against the target government [15]. Kydd and Walter [12] classify one possible motivation for terrorism as an attempt to provoke targets into overreactions that turn public opinion into support for terrorists. Wright [25] asserts that one of Osama bin Laden's goals in implementing the attacks of 9/11 was to draw al-Qaida's opponents into responses that turn out to be repressive blunders, thereby encouraging attacks by other Muslims. Furthermore, while backlash is most closely associated with $M$-types, Jacobson and Kaplan [11] argue that politically motivated Palestinian terrorists have been aided by the downstream benefits of recruitment spurred by Israel's heavy-handed responses to terrorism. To capture this influence, a backlash effect, $b$, replaces $u$ as the source of second-period resources subsequent to a spectacular if the government does not concede. The loss of $u$ is an opportunity cost of a spectacular - i. e., erosion. Effectively, terrorists recognize that they are trading backlash support for grassroot support when they conduct a spectacular that does not lead to concessions. The net benefit of a spectacular on second-period resources is discounted by $\beta$ if no concessions are received, and by $\delta$ if second-period resources are used in a second-period 
attack. $M$-types attack in the second period, whereas $P$-types do not. We assume that $\beta>\delta$ because a spectacular attack causes a target government to raise its defenses, thereby decreasing the effectiveness or raising the cost of a second-period attack by reducing the logistical probability of success. If terrorists must substitute into an alternative form of attack that requires the acquisition of new tactical skills, then this may also result in $\beta>\delta$, following a spectacular incident. The benefits of policies that translate into $\delta$ come at a cost of inducing a backlash effect in support of the terrorist group. If, by contrast, the government concedes, this translates into second-period cost $S$ to the government. At nodes 1 and 4, nonconcession results in zero-sum payoffs for the government and $M$-type terrorists.

Definition 4. Assessment $\left(s_{P}, s_{M},\left(s_{G_{i}}\right)_{i=A, a},\left(\mu_{j}\right)_{j=1}^{4}\right)$ is a perfect Bayes-Nash equilibrium (PBE) for our signaling game if and only if

1. $s_{P}$ and $s_{M}$ are the strategies of $P$-types and $M$-types, respectively;

2. $s_{G_{A}}$ is the government's strategy at information set $G_{A}$ and $s_{G_{a}}$ is its strategy $G_{a}$;

3. $\mu_{i}$ is the government's belief that it is at node ' $i$ ' where (i) $\mu_{i}$ is constructed to be consistent with Bayes rule for actions that are on-the-equilibrium path, and (ii) $\mu_{i}$ is consistent with the expected payoff maximization for strategies that are off-the-equilibrium-path; and

4. the expected payoffs associated with this assessment are mutual best replies.

Intuitively, a PBE is a Nash equilibrium in expected payoffs. As in Arce and Sandler [4], this game contains a (separating) PBE where the government concedes to militant types who attack at the spectacular level and does not concede to political types who attack at the non-spectacular level. There are also (pooling) PBE where both types attack at level $A$ (and the government concedes) or attack at level $a$ (and the government does not concede).

Here, we concentrate on a new equilibrium that is a direct consequence of our introduction of backlash and erosion effects into the signaling framework. Under a spectacular attack, the government is at information set $G_{A}$ and forms (conditional) beliefs that it is at node $1\left(\mu_{1}\right)$ versus node $2\left(\mu_{2}\right)$. From Fig. 6 , the government does not concede subsequent to a spectacular attack if:

$$
-\mu_{2} A-\mu_{1}[A+\delta(R-A)+\delta b] \geq-\mu_{2}[A+\beta S]-\mu_{1}[A+\beta S] .
$$

Since $\mu_{1}+\mu_{2}=1$, Eq. (10) implies that:

$$
\beta S /[\delta(R-A)+\delta b] \geq \mu_{1} .
$$

If the government's belief that it is facing an $M$-type, $\mu_{1}$, is sufficiently low, then it does not concede subsequent to a spectacular attack. A novel result is that the greater the backlash effect, $b$, the more inclined is the government to concede following a spectacular attack. In contrast, the government is more apt to hold firm as the costs of concession, $S$, increases. Hence, understanding the potential for backlash is a key component of counterterror policy.

The government does not concede subsequent to a non-spectacular attack, $a$, when: 


$$
-\mu_{3} a-\mu_{4}[a+\beta(R-a)+\beta u] \geq-\mu_{3}[a+\beta S]-\mu_{4}[a+\beta S] .
$$

Solving for $\mu_{4}$ we have:

$$
\beta S /[\beta(R-a)+\beta u] \geq \mu_{4} .
$$

Under such an attack, the government's belief that it is facing an $M$-type, $\mu_{4}$ must be sufficiently low to justify a commitment to suffer a potential second-period attack rather than face the cost of concessions, $S$.

Given $N$ at $G_{A}$ and $n$ at $G_{a}, P$-types will attack at the spectacular level if

$$
R-A+\beta b \geq R-a+\beta u \text {; i. e., } b \geq u+(A-a) / \beta .
$$

The importance of backlash is immediately apparent; if $b \leq u$ so that the backlash produced by the government's response to the spectacular does not increase support for the terrorists above the existing underlying level, then the condition in (14) cannot be met and $P$-types do not attack at the spectacular level (given $N$ and $n$ ). Furthermore, $M$-types conduct a spectacular if

$$
A+\delta(R-A)+\delta b \geq a+\beta(R-a)+\beta u .
$$

Simplifying and solving for $b$, and combining this with (14), both types attack at the spectacular level if

$$
b \geq \max \left\{u+\frac{(A-a)}{\beta}, \frac{\beta u+(\beta-\delta) R+(1-\beta) a-(1-\delta) A}{\delta}\right\} .
$$

In other words, a (pooling) PBE occurs where both political and militant terrorists attack at the spectacular level and the government does not concede if Eqs. (11), (13), and (16) hold. From Bayes' rule, $\mu_{1}$ equals the prior probability that terrorists are militant types $\left(p_{M}\right)$; hence, Eq. (11) translates into the requirement that the prior probability of $M$-types is low. Because Eq. (13) corresponds to a belief that is offthe-equilibrium-path, not conceding is rational if the initial level of support, $u$, is low; i. e., $P$-types would attack at level $a$ to conserve the resources that they have. The beliefs at $G_{a}$ are therefore consistent with forward induction.

This equilibrium captures several phenomena previously absent in signaling models of terrorism. First, terrorism is rarely successful. Abrams [2] presents a scorecard of terrorist activity since 2001 and notes that terrorist objectives were obtained in only seven percent of the cases. In this equilibrium, terrorists attack at a spectacular level, but do not receive concessions. Second, an actual terrorist campaign occurs. $M$-types attack again subsequent to a spectacular, with the level of attack given as a function of the backlash to the target government's response to the spectacular. Third, this backlash effect must more than offset the current underlying support for the terrorist cause. This can be seen by examining the first term in braces on the right-hand side of Eq. (16). The size of the backlash effect must exceed the current underlying support, $u$, plus a multiple of the resources lost in mounting the spectacular, $(A-a) / \beta$. Terrorists must account for the degree to which spectac- 
ular attacks erode existing support. As Abrams [2] notes in his scorecard, groups that were successful in attaining their goals focused on military - rather than civilian - targets. Less erosion takes place when the target is military. Furthermore, our backlash result has a direct implication for counterterror policy, because defensive measures are less apt to promote a backlash effect whereas proactive ones are more likely to do so.

\section{Concluding Remarks}

This chapter has explored counterterror policy from the perspective of strategic complements - when the actions of one party cause another to act in a similar fashion as is often the case in defensive counterterrorism policy, and strategic substitutes when the actions of one party can replace those of another - as is the case for proactive counterterror policy. Collective action issues, relating to a dichotomy between Pareto-efficient and Nash equilibrium policies arise in these cases. Moreover, when a leader-follower structure is appropriate, our analysis identifies when policies are at cross-purposes, insofar as improving the welfare of one actor comes at the expense of the other actor. A novel insight is that in mixed models, involving both strategic substitutes and complements, this characterization may disappear, with both parties recognizing the mutual benefits or costs of leader-follower behavior. An example of the latter is government leadership when terrorists employ their tactics to garner further popular support.

The issue of how terrorist actions and government responses intersect to produce future resources and support for terrorists is one that is receiving increasing attention. The idea that a government response may generate a backlash against the government itself is embedded within a signaling game, where the government has incomplete information about the terrorists' intent. When combined with the previously unexplored idea that terrorist spectaculars that produce collateral damage may erode support for the terrorists, a trade-off is identified in which spectacular attacks occur only when government reactions produce the requisite backlash. This suggests that counterterrorism policy and intelligence should judiciously account for the net effects of backlash and erosion.

\section{References}

1. Abrams, M.: Al Qaeda's Scorecard: A Progress Report on Al Qaeda's Objectives. Stud. Confl. Terror. 29, 509-529 (2006)

2. Abrams, M.: Why Terrorism Does Not Work. Int. Security 31, 42-78 (2006)

3. Arce, D.G., Sandler, T.: Counterterrorism: A Game-Theoretic Analysis. J. Conflict Resolution 49, 183-200 (2005)

4. Arce, D.G., Sandler, T.: Terrorist Signaling and the Value of Intelligence. Brit. J. Polit. Sci. 37, 573-586 (2007) 
5. Bulow, J.L., Geanakoplos, J.D., Klemperer, P.D.: Multimarket Oligopoly: Strategic Substitutes and Complements. J. Polit. Economy 93, 488-511 (1985)

6. Eaton, B.C.: The Elementary Economics of Social Dilemmas. Can. J. Econ. 37, 805-829 (2004)

7. Enders, W., Sandler, T.: The Political Economy of Terrorism. Cambridge University Press, Cambridge (2006)

8. Faria, J., Arce, D.G.: Terrorism Support and Recruitment. Defence Peace Econ. 16, 263-273 (2005)

9. Hoffman, B.: Inside Terrorism. Columbia University Press, New York (1998)

10. Hoffman, B., McCormick, G.H.: Terrorism, Signaling, and Suicide Attacks. Stud. Confl. Terror. 27, 243-81 (2004)

11. Jacobsen, D., Kaplan, E.H.: Suicide Bombings and Targeted Killings in (Counter-) Terror Games. J. Conflict Resolution 51, 772-792 (2007)

12. Kydd, A.H., Walter, B.: The Strategies of Terrorism. Int. Security 31, 49-80 (2006)

13. Lapan, H.E., Sandler, T.: Terrorism and Signaling. Europ. J. Polit. Economy 9, 383-97 (1993)

14. Overgaard, P.B.: The Scale of Terrorist Attacks as a Signal of Resources. J. Conflict Resolution 38, 452-78 (1994)

15. Rapoport, D.C.: Terrorism. In: Hawkesworth, M., Kogan, M. (eds.) Routledge Encyclopedia of Government and Politics, vol. 2, pp. 1067-1070. Routledge, London (1992)

16. Sandler, T., Arce, D.G.: Terrorism \& Game Theory. Simulat. Gaming 34, 319-37 (2003)

17. Sandler, T., Arce, D.G.: Terrorism: A Game-Theoretic Analysis. In: Sandler, T., Hartley, K. (eds.) Handbook of Defense Economics, Vol. 2 Defense in a Globalized World, pp. 775-813. North-Holland, Amsterdam (2007)

18. Sandler, T., Lapan, H.E.: The Calculus of Dissent: An Analysis of Terrorists' Choice of Targets. Synthèsis 76, 245-261 (1988)

19. Sandler, T., Siqueira, K.: Global Terrorism: Deterrence versus Preemption. Can. J. Econ. 39, 1370-1387 (2006)

20. Sandler, T., Siqueira, K.: Games and Terrorism: Recent Developments. Simulat. Gaming 40, forthcoming (2009)

21. Scheuer, M.: Through Our Enemies' Eyes, revised edition. Potomac Books, Washington, DC (2006)

22. Siqueira, K.: Political and Militant Wings within Dissident Movements and Organizations. J. Conflict Resolution 49, 218-236 (2005)

23. Siqueira, K., Sandler, T.: Terrorists versus the Government: Strategic Interaction, Support, and Sponsorship. J. Conflict Resolution 50, 878-898 (2006)

24. Siqueira, K., Sandler, T.: Terrorist Backlash, Terrorism Mitigation, and Policy Delegation. J. Public Econ. 91, 1800-1815 (2007)

25. Wright, L.: The Looming Tower. Knopf, New York (2006)

26. Wright, L.: The Rebellion Within. The New Yorker, June 2, 37, 16 (2008) 